\title{
Improved Signal Injection Based Sensorless Technique for PM Brushless AC Drives
}

\author{
Y. Li, Z. Q. Zhu, C. M. Bingham, and D. Howe
}

\begin{abstract}
The accuracy of rotor position estimation in the conventional signal injection based sensorless control of permanent magnet brushless $\mathrm{AC}$ drives depends on the load current. This paper proposes an improved method, which significantly reduces the estimation error by accounting for the cross-coupling effect between the $d-$ and q-axes. The conventional and proposed methods are described and their performance is compared by both simulation and experiment.
\end{abstract}

\section{INTRODUCTION}

$\mathrm{F}$ or permanent magnet (PM) brushless AC (BLAC) drives, its accurate rotor position is required in order to provide 3-phase current references for torque control. It is usually obtained directly from an encoder or a resolver, which is mechanically fixed on the motor shaft. However, the rotor position sensor not only increases the hardware and maintenance cost, as well as the system complexity, but also reduces the reliability of the system. It is desirable to estimate the rotor position indirectly from the voltage and current of the BLAC motor.

Many back-EMF-based rotor position estimation methods have been developed for PM BLAC motors [1] [2] [3]. In all of these methods, the rotor position is estimated from the voltage equation, and their differences are the rotor position and speed estimation methods, such as flux-linkage observer, fuzzy logic, EKF, etc. The back-EMF-based rotor position estimation method can precisely predict the actual rotor position if accurate stator inductances and resistances are known. However, since the back-EMF is proportional to the rotor speed, it is very small at low speed and does not exist at zero speed. Therefore, the back-EMF-based sensorless methods cannot start the motor and may fail at low speeds.

Signal injection based sensorless method is developed to estimate the rotor position at low speed or zero speed for machines which exhibit rotor magnetic saliency. The injected signal is usually of high frequency, and the rotor position is estimated from the high frequency voltage equation. Three types of injected signals, i.e., sinusoidal carrier, PWM, and INFORM pulse, are reported in literature [4]-[12].

To avoid introducing extra injected harmonic current, the PWM signals which are inherent in the inverter output are considered to be the injected signal in [4] [5]. As the fundamental frequency of PWM voltage signal is very high

Y. Li, Z. Q. Zhu, C. M. Bingham, and D. Howe are with Department of Electronic and Electrical Engineering, University of Sheffield, Mappin Street, Sheffield S1 3JD, UK. (email: yi.li@shef.ac.uk, z.q.zhu@shef.ac.uk, c.bingham@shef.ac.uk, d.howe@shef. ac.uk). (several $\mathrm{kHz}$ ), and its amplitude cannot be changed as it is determined by the DC-link voltage and the PWM duty cycle, the amplitude of high frequency current will be too small for the motor having a large stator inductance. Thus, the PWM signal injection method may fail if the $\mathrm{AD}$ converter has a low accuracy and the high frequency current signal of the drive has a low signal-to-noise ratio. Specially designed high speed $\mathrm{AD}$ converter, trigger circuit and data buffers are required in order to sample the critical points on the high frequency current waveform which, as mentioned above, is usually several $\mathrm{kHz}$, identical to the PWM frequency. This will significantly increase the cost and complexity of the drive system. In addition, since the method is based on the detection of winding inductances and its accuracy is influenced by the magnetic saturation.

The INFORM pulse [6] [7] is used to avoid the problems in PWM injection method. In the INFORM pulse injection method, the amplitude of injected signal is large, but it is an intermittent signal in order to reduce the average injected power. The pulse width, amplitude, duty cycle of the INFORM injected signal can be set to a reasonable value, and it can avoid using high accuracy and specially designed current sampling hardware. As the injected signal is intermittent, the estimation values of rotor position are discrete and cannot be corrected continuously. This may deteriorate the dynamic performance of the INFORM pulse injection sensorless method.

The most popular high frequency signal is using sinusoidal carrier voltage signal. This method was originally developed for induction motors and recently extended to PM BLAC motor with saliency [8] [9]. However, the identification of the initial rotor polarity was not reported in [8] [9] and was subsequently addressed in [10] [11], in which sine and cosine terms of the $2^{\text {nd }}$ harmonic in $d$-axis current were compared to identify the rotor polarity. In the above papers, the BLAC motors under consideration have salient rotor poles. It was extended in [12] to a non-salient BLAC motor with surface-mounted PM rotor by utilizing the saliency which was induced by magnetic saturation. The high frequency signal in this type of sensorless method is simple to analyze and its current amplitude is controllable. However, as an extra harmonic current signal is introduced into the motor stator, it will cause undesirable acoustic noise, torque ripple and loss.

This paper firstly describes the conventional signal injection based sensorless control method in section II. Then, an improved method, which accounts for the influence of cross-coupling effect between the d-and q-axes, is developed in section III. Simulated and measured results are compared in section IV to illustrate the advantages of the proposed method. 


\section{Conventional High Frequency Signal Injection METHOD [12]}

For a 3-phase BLAC motor, when the cross-coupling between $d$ - and $q$-axes is neglected, the $d$ - and $q$-axis voltage equations for the high frequency components are given by

$$
\left[\begin{array}{c}
v_{d h} \\
v_{q h}
\end{array}\right]=\left[\begin{array}{cc}
L_{d h} & 0 \\
0 & L_{q h}
\end{array}\right] \cdot p\left[\begin{array}{l}
i_{d h} \\
i_{d q}
\end{array}\right]
$$

where $v_{c h}, v_{q h}, i_{c h}, i_{q h}$ are the high frequency components of $d$ and $q$-axis voltages and currents, and $L_{d h}$ and $L_{q h}$ are the $d$ and $q$-axis incremental inductances, respectively. $p=d / d t$.

Since the actual rotor position $\theta_{r}$ is unavailable, the estimated rotor position $\theta_{e}$ is obtained from the observer. The $d q$-axis voltages and currents in (1) are required to be transformed from the actual rotor position reference frame to the estimated rotor position reference frame, i.e.

$$
\left[\begin{array}{l}
v_{d h}^{e} \\
v_{q h}^{e}
\end{array}\right]=T(\Delta \theta)\left[\begin{array}{l}
v_{d h}^{r} \\
v_{q h}^{r}
\end{array}\right],\left[\begin{array}{l}
i_{d h}^{e} \\
i_{q h}^{e}
\end{array}\right]=T(\Delta \theta)\left[\begin{array}{l}
i_{d h}^{r} \\
i_{q h}^{r}
\end{array}\right]
$$

where $\Delta \theta=\theta_{e}-\theta_{r}$ is the difference between the estimated rotor position and the actual rotor position, and $T(\Delta \theta)$ is the coordinate rotating matrix and is given by:

$$
T(\Delta \theta)=\left[\begin{array}{cc}
\cos (\Delta \theta) & \sin (\Delta \theta) \\
-\sin (\Delta \theta) & \cos (\Delta \theta)
\end{array}\right]
$$

Therefore, the high frequency voltage equation in the estimated rotor reference frame is obtained by multiply ing the rotating matrix $T(\Delta \theta)$ on both sides of (1).

$$
\begin{aligned}
& {\left[\begin{array}{c}
v_{d h}^{e} \\
v_{q h}^{e}
\end{array}\right]=T(\Delta \theta)\left[\begin{array}{l}
v_{d h}^{r} \\
v_{q h}^{r}
\end{array}\right]} \\
& =T(\Delta \theta)\left[\begin{array}{cc}
L_{d h} & 0 \\
0 & L_{q h}
\end{array}\right] p\left[\begin{array}{c}
i_{d h}^{r} \\
i_{q h}^{r}
\end{array}\right] \\
& =T(\Delta \theta)\left[\begin{array}{cc}
L_{d h} & 0 \\
0 & L_{q h}
\end{array}\right] T^{-1}(\Delta \theta) \cdot p\left[\begin{array}{c}
i_{d h}^{e} \\
i_{q h}^{e}
\end{array}\right] \\
& =\left[\begin{array}{cc}
L_{a v g}-L_{d i f} \cos (2 \Delta \theta) & L_{d i f} \sin (2 \Delta \theta) \\
L_{d i f} \sin (2 \Delta \theta) & L_{a v g}+L_{d i f} \cos (2 \Delta \theta)
\end{array}\right] p\left[\begin{array}{c}
i_{d h}^{e} \\
i_{q h}^{e}
\end{array}\right]
\end{aligned}
$$

where $L_{\text {covg }}$ and $L_{\text {dif }}$ are defined as:

$$
\left\{\begin{array}{l}
L_{a v g}=\left(L_{q h}+L_{d h}\right) / 2 \\
L_{d i f}=\left(L_{q h}-L_{d h}\right) / 2
\end{array}\right.
$$

When the high frequency sinusoidal voltage, $v_{\text {sig, }}$ is applied to the estimated d-axis, i.e., $v_{d h h}^{e}=v_{\text {sig }}, v_{q h}^{e}=0$, (4) becomes:

$$
\left[\begin{array}{c}
v_{s i g} \\
0
\end{array}\right]=\left[\begin{array}{cc}
L_{a v g}-L_{d i f} \cos (2 \Delta \theta) & L_{d i f} \sin (2 \Delta \theta) \\
L_{d i f} \sin (2 \Delta \theta) & L_{a v g}+L_{d i f} \cos (2 \Delta \theta)
\end{array}\right] p\left[\begin{array}{c}
i_{d h}^{e} \\
i_{q h}^{e}
\end{array}\right](6)
$$

The $d q$-axis high frequency currents in estimated rotor reference frame are obtained by solving (6):

$$
\left\{\begin{array}{l}
i_{d h}^{e}=\frac{v_{s i g}}{p\left(L_{a v g}^{2}-L_{d i f}^{2}\right)}\left[L_{a v g}+L_{d i f} \cos (2 \Delta \theta)\right] \\
i_{q h}^{e}=-\frac{v_{s i g}}{p\left(L_{a v g}^{2}-L_{d i f}^{2}\right)} L_{d i f} \sin (2 \Delta \theta)
\end{array}\right.
$$

If the estimation error of rotor position $\Delta \theta$ is sufficiently small, it can be simplified as:

$$
\Delta \theta \approx \frac{\left(L_{a v g}^{2}-L_{d i f}^{2}\right) p i_{q h}^{e}}{-2 v_{\text {sig }} L_{d i f}}=k_{H F}^{\Delta \theta} \cdot i_{q h}^{e}
$$

where $k_{H F}^{\Delta \theta}=\frac{\left(L_{a v g}^{2}-L_{d i f}^{2}\right) p}{-2 v_{s i g} L_{d i f}}$.

As the error in the estimated rotor position is proportional to the $q$-axis high frequency current in estimated rotor reference frame, $i_{q h}{ }^{e}$, it can be controlled to zero by controlling $i_{q h}{ }^{e}=0$ [12].

\section{IMPROVED HIGH FREQUENCY SIGNAL INJECTION METHOD}

For a 3-phase BLAC motor, when the cross-coupling between $d$ - and $q$-axes is considered, the $d$ - and $q$-axis voltage equations for the high frequency components are given by:

$$
\left[\begin{array}{c}
v_{d h} \\
\mathcal{v}_{q h}
\end{array}\right]=\left[\begin{array}{cc}
L_{d h} & L_{d q h} \\
L_{q d h} & L_{q h}
\end{array}\right] \cdot p\left[\begin{array}{l}
i_{d h} \\
i_{d q}
\end{array}\right]
$$

where $L_{d q h}$ and $L_{q d h}$ are the incremental mutual-inductances between $d$ - and $q$-axis.

By way of example, Fig. 1 shows typical finite element predicted variation of incremental self- and mutual-inductances with the load current, $i_{q}$, due to magnetic saturation. For the interior permanent magnet (IPM) BLAC motor under consideration, Table I, $L_{c h} L_{q h}$ and $L_{d q h}$ are $25 \mathrm{mH}$ $32 \mathrm{mH}$ and $-7 \mathrm{mH}$, respectively, when $i_{d}=0 \mathrm{~A}$ and $i_{q}=4 \mathrm{~A}$. Clearly, since the magnitude of $L_{d q h}$ is comparable with that of $L_{c h}$ and $L_{q h}$, its influence cannot be neglected in the high frequency voltage equations.

Equation (9) can be transformed to its estimated rotor reference frame by multiplying $T(\Delta \theta)$ on both sides.

$$
\left[\begin{array}{c}
v_{d h}^{e} \\
v_{q h}^{e}
\end{array}\right]=\left[\begin{array}{cc}
L_{a v g}-\hat{L}_{d i f} \cos \left(2 \wedge \theta+\theta_{m}\right) & \hat{L}_{d i f} \sin \left(2 \wedge \theta+\theta_{m}\right) \\
\hat{L}_{d i f} \sin \left(2 \wedge \theta+\theta_{m}\right) & L_{a v g}+\hat{L}_{d i f} \cos \left(2 \wedge \theta+\theta_{m}\right)
\end{array}\right] p\left[\begin{array}{c}
i_{d h}^{e} \\
i_{q h}^{e}
\end{array}\right]
$$

where $\left\{\begin{array}{l}\theta_{m}=\arctan \left(L_{d q h} / L_{d i f}\right) \\ \hat{L}_{d i f}=\sqrt{L_{d i f}^{2}+L_{d q h}^{2}}\end{array}\right.$

Since the high frequency sinusoidal voltage is applied to the estimated $d$-axis, (10) becomes:

$\left[\begin{array}{c}v_{s i g} \\ 0\end{array}\right]=\left[\begin{array}{cc}L_{a v g}-\hat{L}_{d i f} \cos \left(2 \Delta \theta+\theta_{m}\right) & \hat{L}_{d i f} \sin \left(2 \Delta \theta+\theta_{m}\right) \\ \hat{L}_{d i f} \sin \left(2 \Delta \theta+\theta_{m}\right) & L_{a v g}+\hat{L}_{d i f} \cos \left(2 \Delta \theta+\theta_{m}\right)\end{array}\right] p\left[\begin{array}{c}i_{d h}^{e} \\ i_{q h}^{e}\end{array}\right]$ 
The resulting $d$ - and $q$-axis high frequency currents in the estimated reference frame are obtained by solving (12):

$$
\begin{aligned}
& i_{d h}^{e}=\frac{v_{s i g}}{p\left(L_{a v g}^{2}-\hat{L}_{d i f}^{2}\right)}\left[L_{a v g}+\widehat{L}_{d i f} \cos \left(2 \Delta \theta+\theta_{m}\right)\right] \\
& i_{q h}^{e}=-\frac{v_{s i g}}{p\left(L_{a v g}^{2}-\hat{L}_{d i f}^{2}\right)} \hat{L}_{d i f} \sin \left(2 \Delta \theta+\theta_{m}\right)
\end{aligned}
$$

Thus, if the high frequency component in the $q$-axis current is controlled to be zero, i.e. $i_{q h}{ }^{e}=0$, as was in the conventional signal injection based sensorless scheme [12], an error exists in the estimated rotor position as a result of the incremental mutual inductance, $L_{d q h}$, which exists between $d$ and $q$-axes. The error is given by:

$$
\Delta \theta=-\frac{\theta_{m}}{2}=\frac{1}{2} \arctan \left(\frac{2 L_{d q h}}{L_{d h}-L_{q h}}\right)
$$

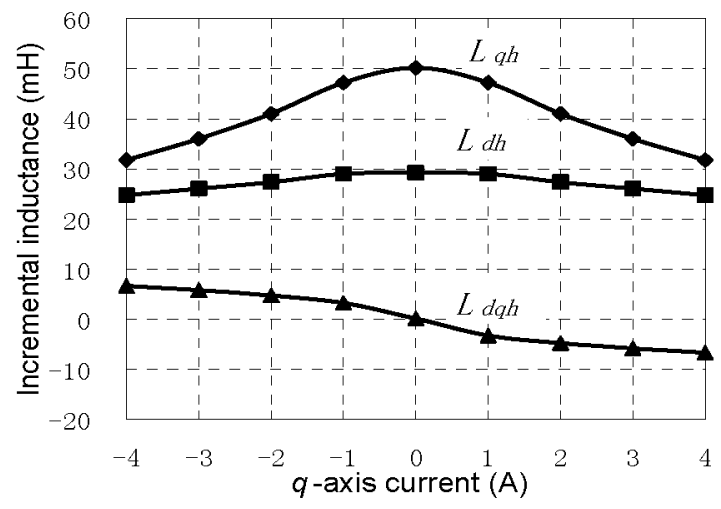

Fig. 1. Finite element predicted incremental $d$ - and $q$-axis self- and mutual-inductances at various $q$-axis current $\left(i_{d}=0 \mathrm{~A}\right)$.

Fig. 2 shows the error in estimated rotor position of conventional signal injection based sensorless control of the prototype IPM BLAC motor under $i_{c h}{ }^{2}=0$ control, which is predicted by using the incremental self- and mutual-inductances in Fig. 1 and (14).

Clearly, the error in the estimated rotor position will only be zero when $L_{d q h}=0$. The stronger the cross-coupling effect between the $d$-and $q$-axes, the larger will be the error in the estimated rotor position. Thus, $i_{q h}{ }^{e}=0$ sensorless estimation strategy in [12] is not suitable for the IPM BLAC motor with large $L_{d q h}$ at heavy load condition. It is necessary to consider the cross-coupling effect to reduce the error in estimated rotor position. In this case, in order to control the rotor position estimation error $\Delta \theta$ to be zero, the high frequency component in the q-axis current should not be controlled to be zero but should be controlled according to (13b) by letting $\Delta \theta=0$, viz.:

$$
i_{q h}^{e}=-\frac{v_{s i g}}{p\left(L_{\text {avg }}^{2}-\hat{L}_{d i f}^{2}\right)} \widehat{L}_{d i f} \sin \theta_{m}
$$

Or more conveniently, it can be controlled according to (16) which is obtained from (13a) and (13b) when $\Delta \theta=0$ :

$$
i_{q h}^{e}=-\left(L_{d q h} / L_{q h}\right) i_{d h}^{e}
$$

Clearly from (16), the accuracy of rotor position estimation depends on the ratio of $L_{d q h} / L_{q h}$ in the improved signal injection based sensorless control. $L_{d q h} / L_{q h}$ varies with $d$ - and $q$-axis currents due to the variation of $L_{d q h}$ and $L_{q h}$. The incremental $d q$-axis self- and mutual-inductances may be predicted by the finite element method or measured by applying various $i_{d}$ and $i_{q}$.

In the proposed improved signal injection based sensorless control method, $i_{q h}{ }^{e}=-\left(L_{d q h} / L_{q h}\right) i_{d h}{ }^{e}$ control strategy is used to make the error in the estimated rotor position to be zero. When the cross-coupling effect is sufficiently small compared with $L_{q h}$, i.e. $L_{d q h} \approx 0$, the control strategy becomes $i_{q h}{ }^{e}=0$, which is identical to the conventional signal injection based sensorless method in section II.

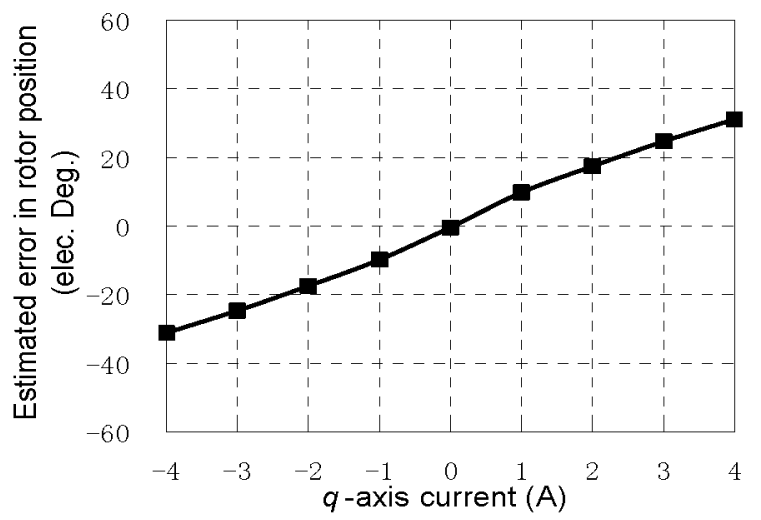

Fig. 2. Estimation error of conventional signal injection based sensorless control.

\section{COMPARISON OF RESUlts OBTAINED By PROPOSED AND CONVENTIONAL METHODS}

The experimental system setup is shown in Fig.3, while the signal injection based sensorless control system is shown in Fig. 4. The parameters of the interior permanent magnet brushless AC motor, whose incremental inductance characteristics were shown in Figs. 1, are given in Table I. The control strategy is implemented on a TMS320C31 DSP, together with a PIC18F4431 MCU, which serves as the PWM generator and the encoder interface. The frequencies of the AD sampling, the speed control loop, and the PWM are all set to $5 \mathrm{kHz}$, and the injected signal is $35 \mathrm{~V}, 330 \mathrm{~Hz}$. The actual rotor position, $\theta_{r}$, is obtained from a 1024 pulse-per-revolution encoder, which is used as a reference for the estimated rotor position $\theta_{r}^{e}$.

\section{TABLE I SPECIFICATION OF BLAC MOTOR}

\begin{tabular}{ll}
\hline Number of pole-pairs & 3 \\
Rated speed & $1000 \mathrm{rpm}$ \\
Rated torque & $4.0 \mathrm{Nm}$ \\
Rated phase voltage (peak) & $158 \mathrm{~V}$ \\
Rated phase current (peak) & $4.0 \mathrm{~A}$ \\
Phase resistance $R_{s}$ & $6.0 \Omega$ \\
\hline
\end{tabular}


As in Fig. 4, there are 3 PID controllers in the experiment system: one is used to control the motor rotational speed, i.e. speed loop, and the other two controllers are used to control the $\mathrm{d}$ - and q-axis currents, i.e. current loops. The PID controller of the speed loop is set as: $K_{\mathrm{P}}=0.2 \mathrm{~A} / \mathrm{Hz}$, $\mathrm{K}_{\mathrm{I}}=0.5 \mathrm{~A} /(\mathrm{Hz} \cdot \mathrm{S})$, and $\mathrm{K}_{\mathrm{D}}=0 \mathrm{~A} /\left(\mathrm{Hz} \cdot \mathrm{S}^{-1}\right)$. The parameters of $\mathrm{d}-$ and $q$-axis current loop controllers are: $\mathrm{K}_{\mathrm{P}}=0 \mathrm{~V} / \mathrm{A}$, $\mathrm{K}_{\mathrm{I}}=5000 \mathrm{~V} /(\mathrm{A} \cdot \mathrm{S})$, and $\mathrm{K}_{\mathrm{D}}=0 \mathrm{~A} /\left(\mathrm{A} \cdot \mathrm{S}^{-1}\right)$.

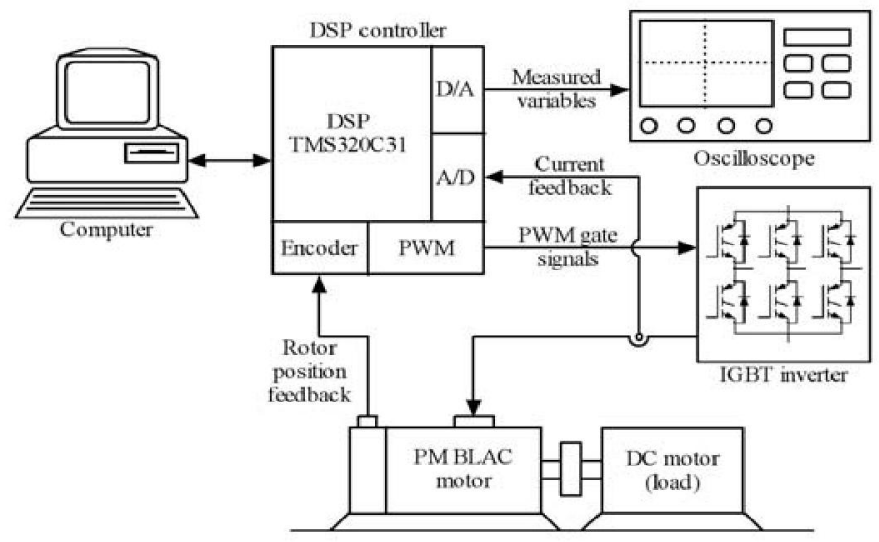

Fig. 3 Experimental test setup.

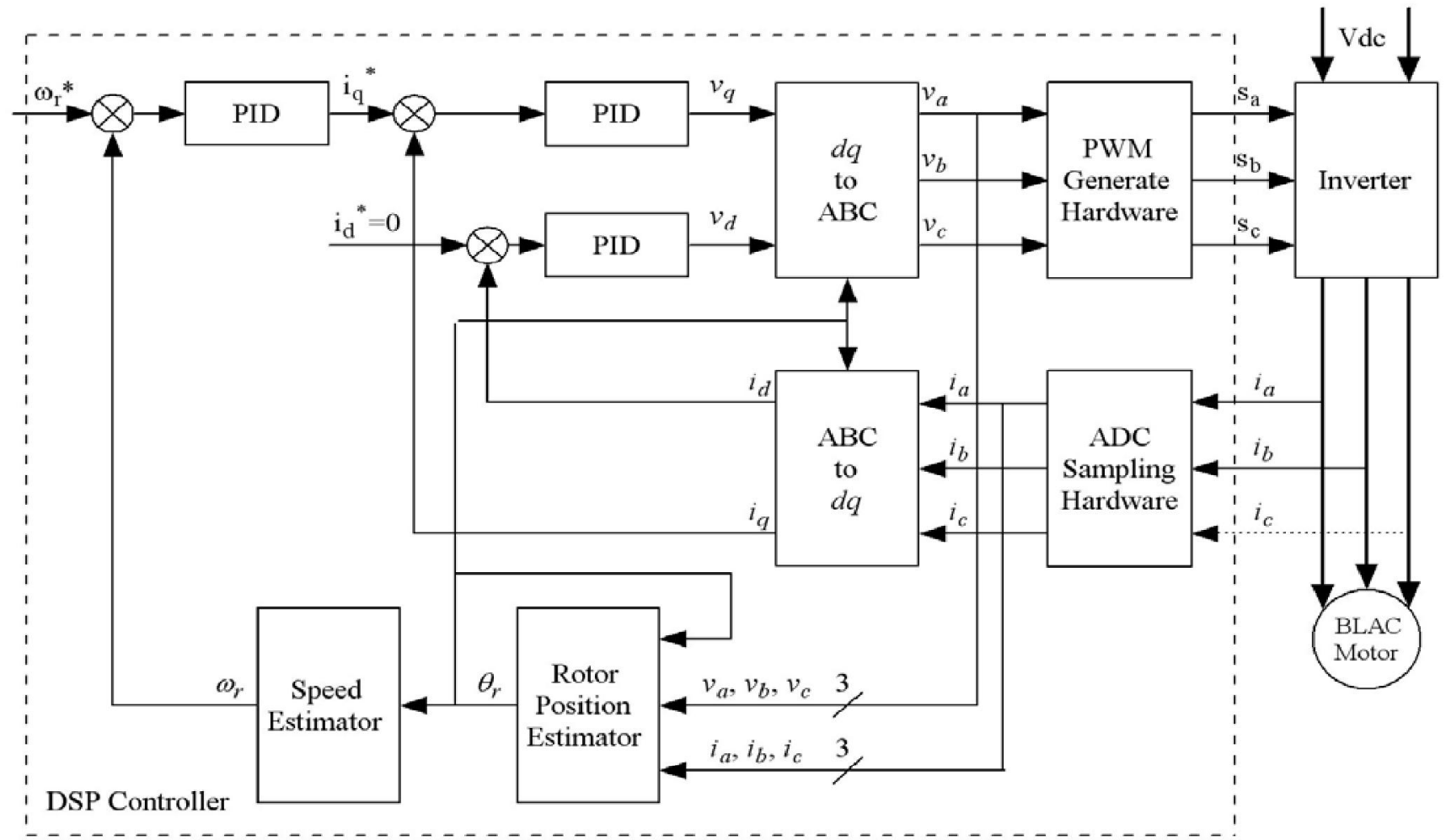

Fig. 4. Sensorless BLAC motor drive system.

Figs. 5 and 6 compare the estimated and actual rotor position when the estimated rotor position is used for position feedback and the rotor speed command is changed from $-10 \mathrm{~Hz}$ to $+10 \mathrm{~Hz}$, i.e., $-200 \mathrm{rpm}$ to $+200 \mathrm{rpm}$. As will be seen in Figs. 5(a) and 6(a), when the conventional signal injection based sensorless scheme is employed, the estimated rotor position error increases significantly with the load current, and is $\sim 25^{\circ}$ when $i_{q}=4 \mathrm{~A}$. By applying the proposed method, this reduces to $\sim 5^{\circ}$,Figs. 5(b) and $6(\mathrm{~b})$. Similar improvement can be seen from simulated and measured results, which clearly demonstrates the effectiveness of the proposed method.

\section{CONCLUSIONS}

In this paper, an improved sensorless method based on signal injection is developed to reduce the error in estimated rotor position due to the neglect of cross-coupling effect in the conventional method. Significant improvement in the estimation accuracy of rotor position has been achieved, as confirmed by both simulation and experiment. 


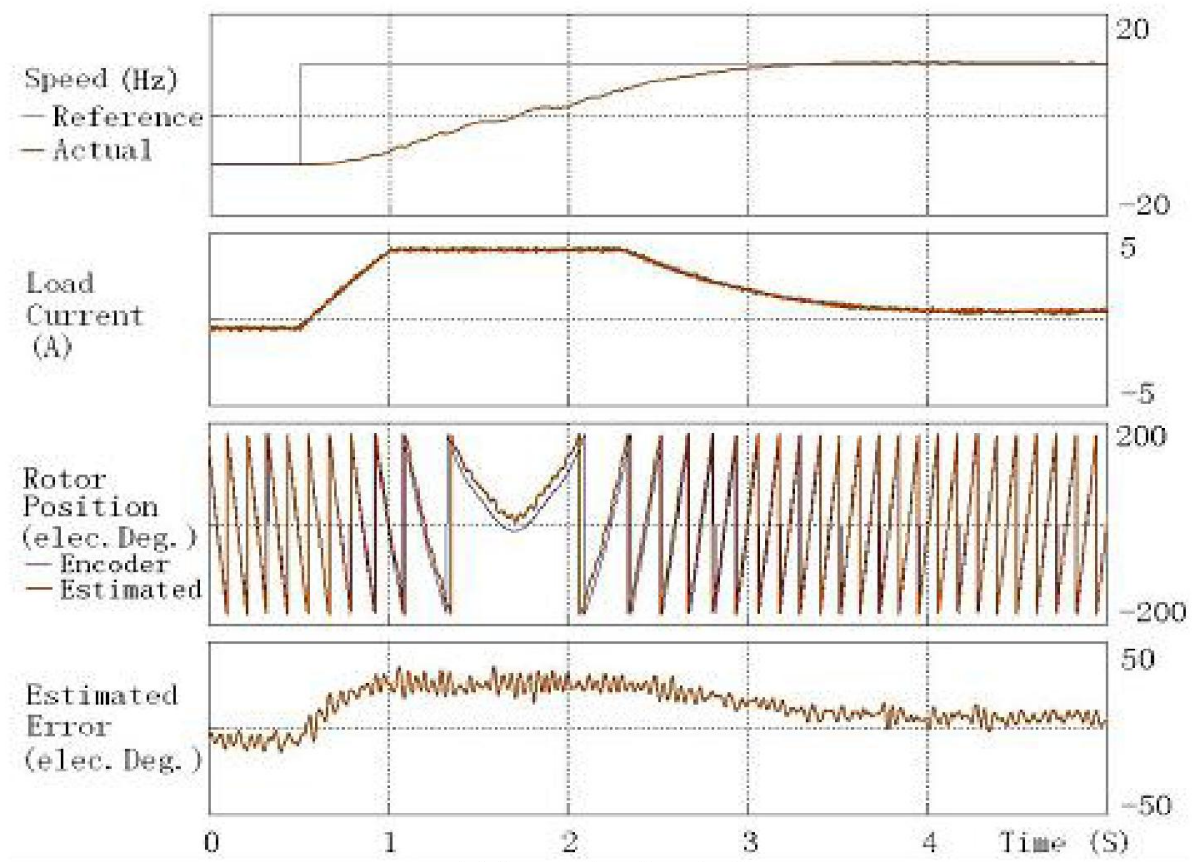

(a) Conventional method

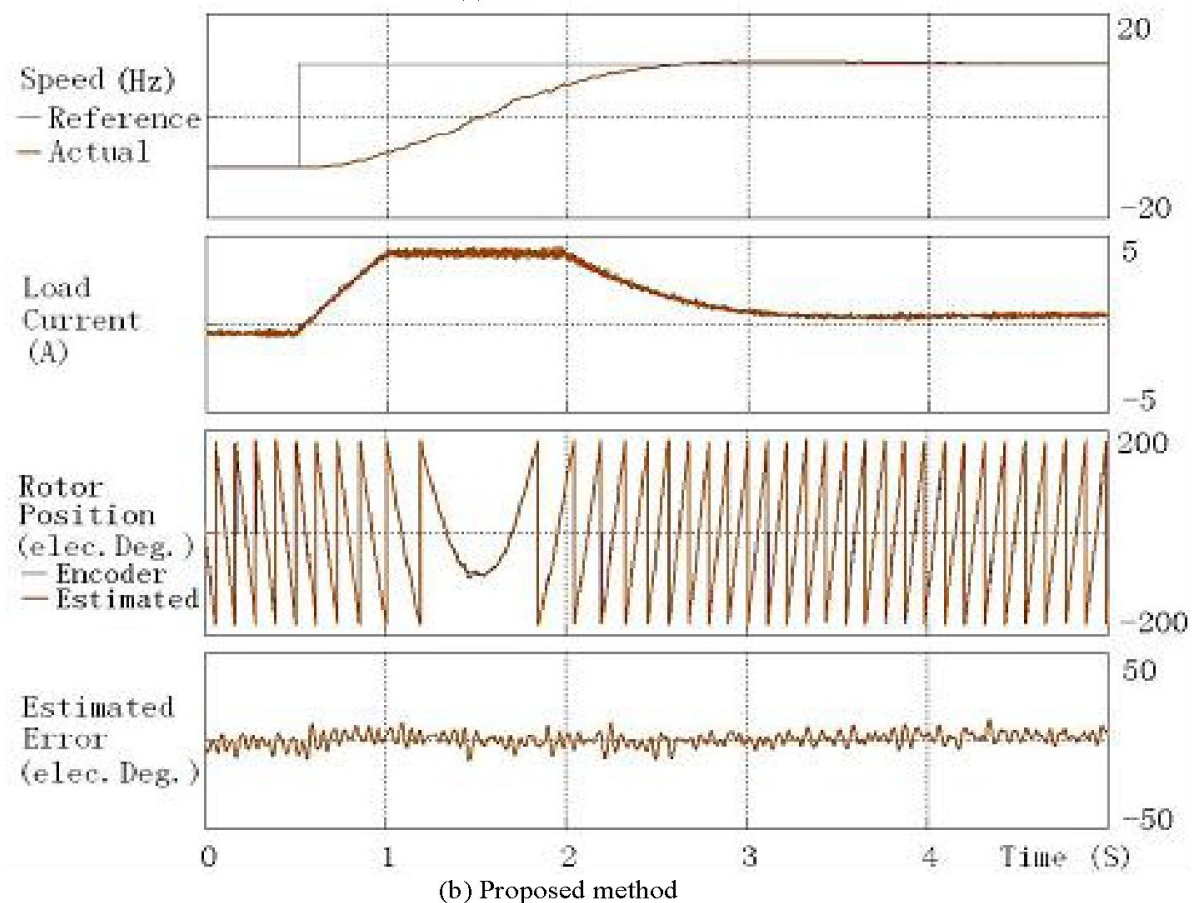

Fig. 5. Simulated step speed response of signal injection based sensorless operation (speed command: $\pm 10 \mathrm{~Hz}$, and $i_{d}=0$ ).

\section{REFERENCES}

[1] K. R. Shouse, D. G. Taylor, "Sensorless velocity control of permanent-magnet synchronous motors," IEEE Trans. Control System Technology, vol. 6, no. 3, pp. 313-324, 1998.

[2] S. Morimoto, K. Kawamoto, M. Sanada, and Y. Takeda, "Sensorless control strategy for salient-pole PMSM based on extended EMF in rotating reference frame," IEEE Trans. Industry Application, vol.38, no.4, pp. 1054-1061, 2002.

[3] Z. Chen, M. Tomita, S. Koki, and S. Okuma, "An extended electromotive force model for sensorless control of interior permanent-magnet synchronous motors," IEEE Trans. Industrial Electronics, vol.50, no.2, pp. 288-295, 2003.

[4] S. Ogasawara, and H. Akagi, "Implementation and position control performance of a position-sen sorless IPM motor drive system based on magnetic saliency," IEEE Trans. Industry Applications, vol.34, no. 4, pp. 806-812, 1998.

[5] C. Wang, and L. Xu, "A novel approach for sensorless control of PM machines down to zero speed without signal injection or special PWM technique," IEEE Trans. Power Electronics, vol. 19, no. 6, pp. 1601-1607, 2004 
[6] M. Schrodl, and M.Lambeck, "Statistic properties of the INFORM method for highly dynamic sensorless control of PM motor down to standstill," Proc. IECON.2003, vol. 2, pp. 1479-1486, 2003

[7] E. Robeischl, and M. Schroed1, "Optimized INFORM measurement sequence for sensorless PM synchronous motor drives with respect to minimum current distortion," IEEE Trans. Industry Applications, vol. 40, no. 2, pp. 591-598, 2004.

[8] M. J. Corley, and R. D. Lorenz, "Rotor position and velocity estimation for a salient-pole permanent magnet synchronous machine at standstill and high speed," IEEE Trans. Industry Application, vol.34, no. 4, pp. 784-789, 1998.

[9] T. Aihara, A. Toba, T. Yanase, A. Mashimo, and K. Endo, "Sensorless torque control of salient-pole synchronous motor at zero-speed operation," IEEE Trans. Power Electronics, vol. 14, no. 1, pp.202-208, 1999.

[10] J.I. Ha, K. Ide, T. Sawa, and S.K. Sul, "Sensorless rotor position estimation of an interior permanent-magnet motor from initial states", IEEE Trans. Industry Applications, vol. 39, no. 3, pp.761-767, 2003.

[11] H. Kim, K.K. Huh, and R.D.Lorenz, "A novel method for initial rotor position estimation for IPM synchronous machine drives," IEEE Trans. Industry Applications, vol. 40, no. 5, pp. 1369-1378, 2004.

[12] J.H. Jang, S.K. Sul, J.I. Ha, K. Ide, and M. Sawamura, "Sensorless drive of surface-mounted permanent-magnet motor by high-frequency signal injection based on magnetic saliency," IEEE Trans. Industry Applications, vol. 39, no. 4, pp. 1031-1039, 2003.
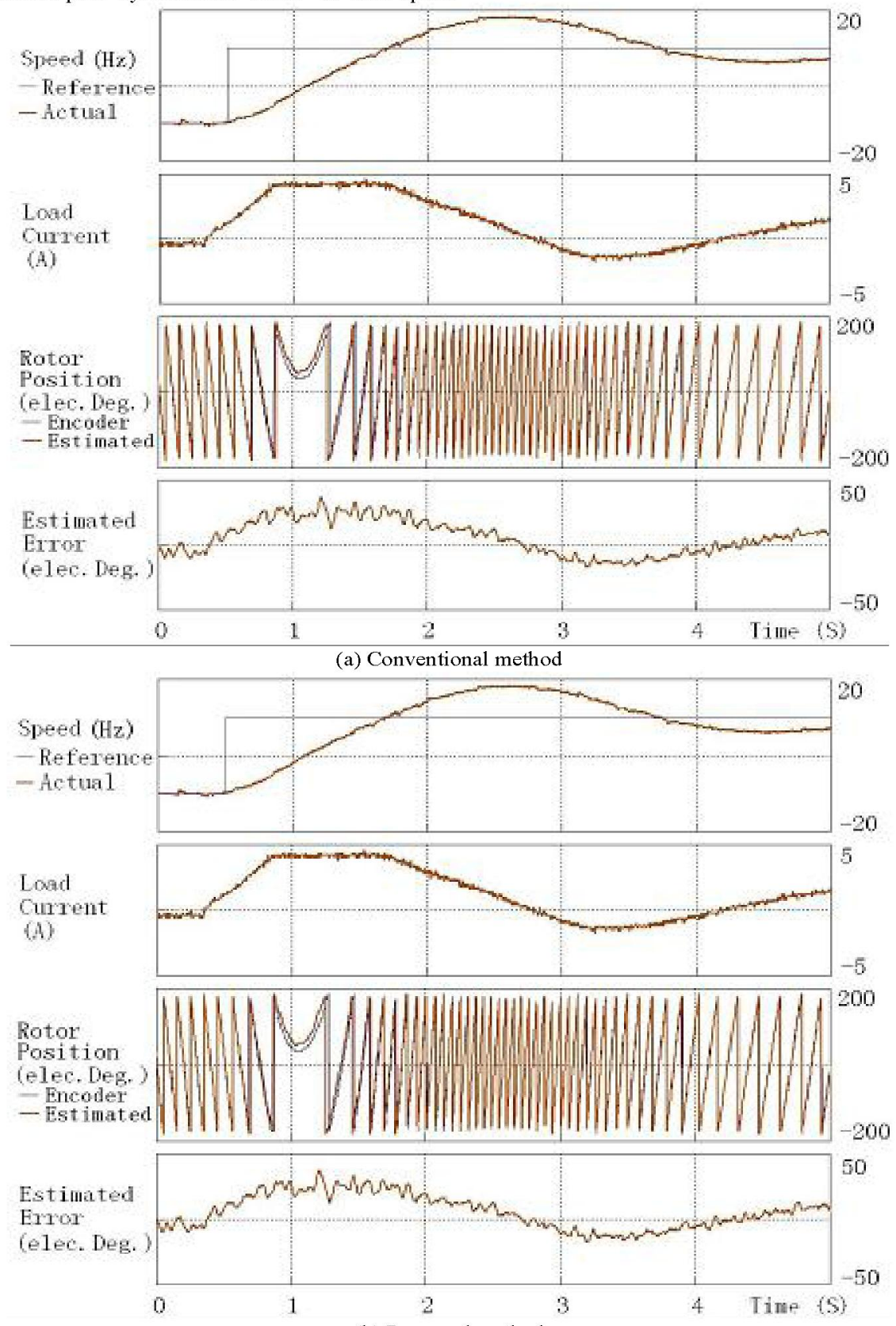

(b) Proposed method

Fig. 6. Measured step speed response of signal injection based sensorless operation (speed command: $\pm 10 \mathrm{~Hz}$, and $i_{d}=0$ 